\title{
POWDER MICROSCOPIC STUDIES OF THE FRUITS OF TRIBULUS TERRESTRIS LINN COLLECTED FROM DIFFERENT GEOGRAPHICAL LOCATIONS OF SOUTH INDIA-A COMPARATIVE STDY
}

\author{
SURESH REDDY YANALA ${ }^{\mathrm{a} *}$, D. SATHYANARAYANA ${ }^{\mathrm{b}}$ \\ a,bDepartment of Pharmacy, Annamalai University, Chidambaram, Tamilnadu, India \\ Email: sureshreddyyanala@gmail.com
}

Received: 22 Sep 2016 Revised and Accepted: 17 Nov 2016

\begin{abstract}
Objective: The aim of present study includes the collection of Tribulus terrestris fruit samples from three geographical locations of south India. Whose powder microscopical characters were assessed by the comparative study by using standard pharmacognostic methods prescribed in standard reference books to ensure quality and identity of all three fruit samples.
\end{abstract}

Methods: Collected fruit samples were shade dried and pulverised to get the coarse powder. Fruit powder has taken on a micro slide and treated with various colouring reagents to give colour to various tissues by following standard pharmacognostic methods prescribed in reference books. The slide was mounted by adding glycerine and observed under the microscope.

Results: The fruits consist of five triangular cocci which develop from the penta carpellary syncarpous ovary. Each coccus has two long sharp and two short spines. All fruits showed significant variation in the diameter, radial length of the coccus and length of the spines. The tomentum in fruit sample 3 is less when compared with fruit samples 1 and 2 . The entire growth period in all geographical regions, the basic characters of cell inclusions like thick-walled parenchyma cells, epidermal, sclerenchymatous, prismatic calcium oxalate crystals and type of cells like sclereids (fibre sclereids and brachy sclereids), trichomes (short, long and thick-walled trichomes) and their pattern of arrangement are almost same.

Conclusion: Three geographically different fruit samples showed variation in the quantity of cell inclusions and size of sclereids, trichomes and wall thickness of parenchymatous, epidermal and sclerenchymatous cells. All three fruit samples showed significant variation in morphological characters. Powder microscopic observation can be employed to detect the source of adulteration in powdered raw medicinal plant materials.

Keywords: Tribulus terrestris Linn, Powder microscopy, Geography, South India

(C) 2016 The Authors. Published by Innovare Academic Sciences Pvt Ltd. This is an open access article under the CC BY license (http://creativecommons.org/licenses/by/4. 0/) DOI: http://dx.doi.org/10.22159/ijpps.2017v9i1.15316

\section{INTRODUCTION}

Tribulus terrestris L. commonly known as Gokhru which belongs to family Zygophyllaceae. It is an annual herb that widely distributed worldwide, especially in warm temperate and tropical regions of Southern Asia, Africa, Europe and in Northern Australia [1]. The fruits of Tribulus terrestris widely used as folk medicine in India, China, Turkey and other countries against male sexual impotency, blood pressure, heart diseases, abdominal dysfunction, edema, eye problems, etc., [2]. Ayurvedic pharmacopoeia describes Tribulus terrestris Linn. as Gokshura and it is used in the preparation of various formulations.

Medicinal plant materials are grouped according to their sensory, macro and microscopic characteristics. An examination of these characteristics is the initial step towards establishing identity and purity of medicinal plant materials. These observations should be conducted before any other further observations are undertaken [3]. Medicinal plant materials are being frequently adulterated/ substituted in common practice due to the number of regions such as similarity in morphological features, confusion in the regional name as written in classical text references, presence of inferior similar active principles in substituting plant materials, collector ignorance etc., resulted in less therapeutic activity of the finished dosage form [4]. For instance, a systematic identification is essential in order to get standardised finished medicinal plant based products. The objective of producing potent, safe and inexpensive plant origin drugs can be achieved by the systematic study of plant material [5].

Microscopy is a reliable method of the tool by which complete powder microscopic characters of the crude drugs can be obtained. Therefore, the detailed powdered microscopic study of the fruits of Tribulus terrestris $\mathrm{L}$. has been carried out to establish its quality and purity of the powdered crude drug. The microscopic examination is used for identification of organised drugs to determine cellular structures by their histological characters and to detect possible adulterant [6]. The Microscopic examination includes an examination of whole plant material, certain morphological plant parts or powdered form of crude drugs.

Morphological characters do not give an exact idea about the identity when crude drugs are in powder form. In such cases, microscopical examination is the only choice [7]. The characters of cell inclusions, type of cells and quantity of cell inclusions (number, size, etc) of medicinal plants are found to fluctuate with geographical regions [8]. Therefore, in the current study fruit samples of Tribulus terrestris were collected on July 2015 from three geographical regions of South India i.e. Telangana, Karnataka, Tamilnadu with a view to establishing standards for their identity, quality, purity. Therefore, the present work was carried out to observe various powder microscopical characters by which the fruit sample can be identified microscopically [9]. The chemical methods of identification of Tribulus terrestris fruit samples will be the scope for future work.

\section{MATERIALS AND METHODS}

Collection, authentication and processing of plant materials

The plant materials for the present work were collected from the wild sources of three regions of South India (Telangana, Karnataka, Tamilnadu states). Due to collection problem and other reasons we didn't collected North India region samples. Care was taken to select healthy plants and normal organs. The identity of the freshly collected plants was primarily confirmed by comparing their morphology mentioned in herbal pharmacopoeias and different floras. The final authenticity of the freshly collected fruit sample was confirmed by Dr. Jayaraman, Director PARC, Tambaram, Chennai 
with authentification numbers PARC/2015/3214 (NakrekalTelangana), PARC/2015/3215 (Bellary-Karnataka), PARC/2015/ 3216 (Katumnar koil-Tamilnadu). The required fruit samples were cut and removed from the plants, washed thoroughly under running tap water to remove the surface adherent impurities. Cleaned fresh fruits were shade dried and were pulverised in a pulverizer for the size reduction, then passed through 60 mesh sieve to collect fine powder for powder microscopic work [10].

\section{Chemicals and reagents}

All chemicals and reagents were analytical grade. Toluidine blue, Phloroglucinol were purchased from S. D Fine Chemicals, Mumbai. Safranin, Iodine, Potassium Iodide and glycerine were procured from HI-MEDIA (Mumbai). Pulverizer (Sree valsa engineering Co. Coimbatore-Model number SVE015) used to get powder form of the crude drug. Canon photo spot G 3 camera attached to microscope was used to take different magnifications of photographs.

\section{Slide preparation and mounting}

The small quantity of powder was placed on slides and then powdered materials were cleared with $\mathrm{NaOH}$ and stained with Toluidine blue reagent [11]. Some cytochemical reactions were observed and also the staining results were remarkably good. The dye showed pink colour to the cellulose walls, blue to the lignified cells, violet to the mucilage and blue to the protein bodies. Cells also stained with safranin and IKI (for Starch). All the powder samples were separately treated with concentrated hydrochloric acid and phloroglucinol [12]. The powder materials were mounted in glycerine medium after staining, and covered with a coverslip. The same observation was done separately for all the samples collected from three different geographical places to identifying cell constituents and measured under the microscope.

\section{Photomicrographs}

Photographs of different magnifications of three fruit samples were taken using Canon photo spot G 3 camera attached to the microscopic unit. The bright field was selected for normal observations. For the microscopic study of starch grains, crystals and lignified cells, the polarised light was employed [13]. Under polarised light, cells appear bright against a dark background. Magnifications of the microscopic fig. are indicated by the scale bars. Descriptive terms of the histological features of the all three fruit samples are as given, with reference to the standard anatomy books [14].

\section{RESULTS}

Powder microscopic results of three fruit samples were mentioned as descriptive statistics (summarised powder microscopic information about each sample).

Sample 1: The fruit sample collected from Nakrekal, Telangana State shows the following micromorphology features. The fruit develops from Penta carpellary syncarpous ovary, giving rise to five fused cocci. Each coccus has two long sharp, strong spines on the outer part and two short, thick spines on the inner part (fig. 1.1,2).

Diameter of the fruit $9 \mu \mathrm{m}$

Radial length of the coccus $3 \mu \mathrm{m}$

Thickness of the coccus along tangential plain $750 \mu \mathrm{m}$

Length of the longest spins $4 \mu \mathrm{m}$

The powder preparation of the fruit shows the following elements

Sclereids: Sclereids are the major components of the powder. These are two types of sclereids.

Fibre sclereids: Fibre sclereids are long narrow fibre like in shape and size; their ends are tapering. The cell walls are very thick, and the cell lumen is wide (fig. 2.2). The sclereids are $150 \mu \mathrm{m}$ long and $20 \mu \mathrm{m}$ thick.

Brachy sclereids (fig. 2.1, 2.3): Short, wide, angular sclereids called brachy sclereids. They are wide, thick-walled, sometimes lobed cells; numerous circular, simple pits are seen on the walls. The sclereids occur in thick bundles, firmly cohering with each other (fig. 2.3).

Parenchyma cells: Large masses of parenchyma cells are often seen in the powder (fig. 3.1). The cells are thin-walled, circular and possess dense cytoplasm. The average diameter of the parenchyma cell is $8 \mu \mathrm{m}$.
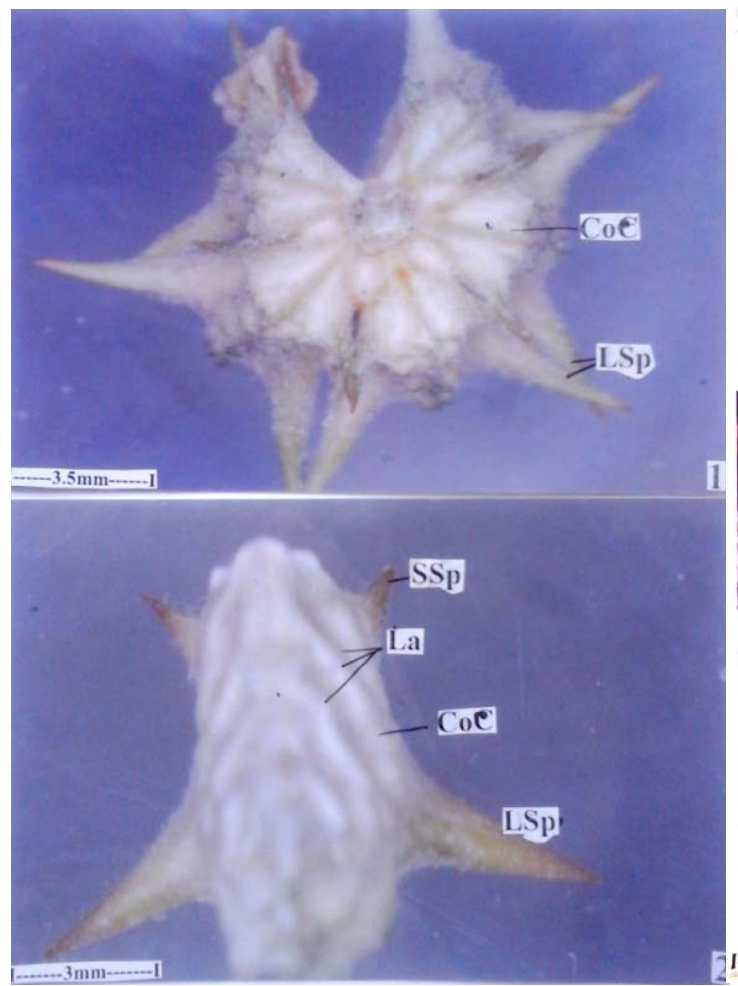

Fig. 1.1, 2

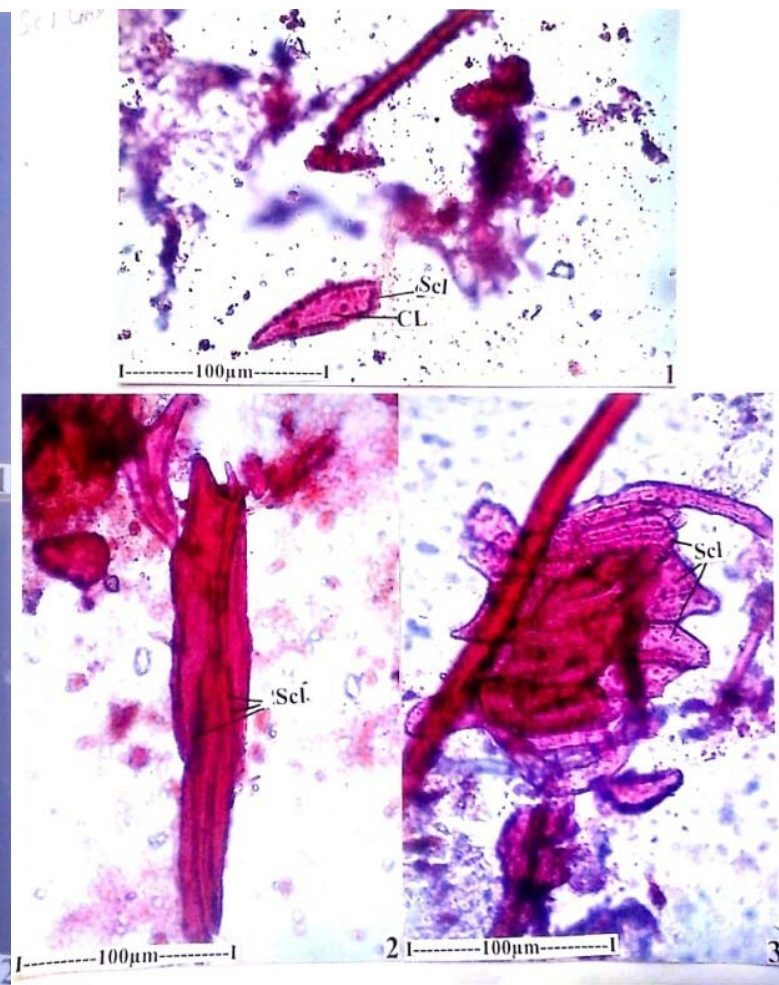

Fig. 2.1, 2, 3 
Trichomes (fig. 3.2; 4.1, 2): Trichomes are abundant on the fruit. They are sheltered in the powder. The trichomes are of different sizes. Some of the trichomes are short, and others are quite long. They are gradually tapering into narrow pointed tips. The short trichomes are less than $200 \mu \mathrm{m}$ long; the longer trichomes are $450 \mu \mathrm{m}$ (fig. 3.2). There are also thick undulate trichomes simulating worms (fig. 4.1).
These vermiform trichomes have wide cell lumen. The trichomes are $10 \mu \mathrm{m}$ thick; their walls strongly lignified (fig. 4.2).

Crystals (fig. 5.1, 2): Calcium oxalate crystals are abundant in the powder. They are the prismatic type. They are cuboidal, rhomboidal or polyhedral types. They are minute or fairly large types.

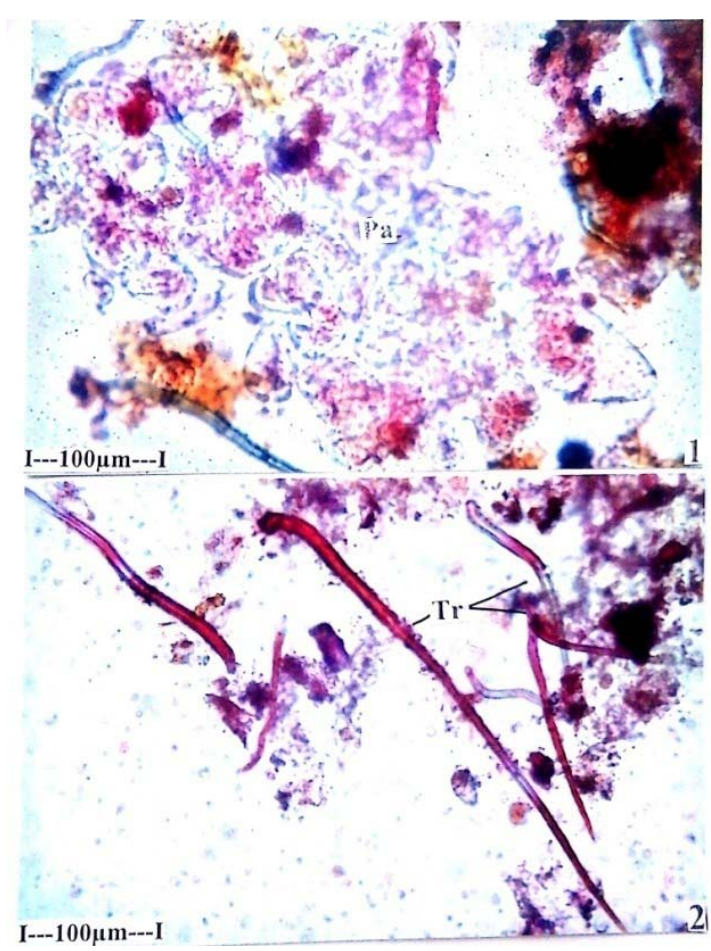

Fig. 3.1, 2

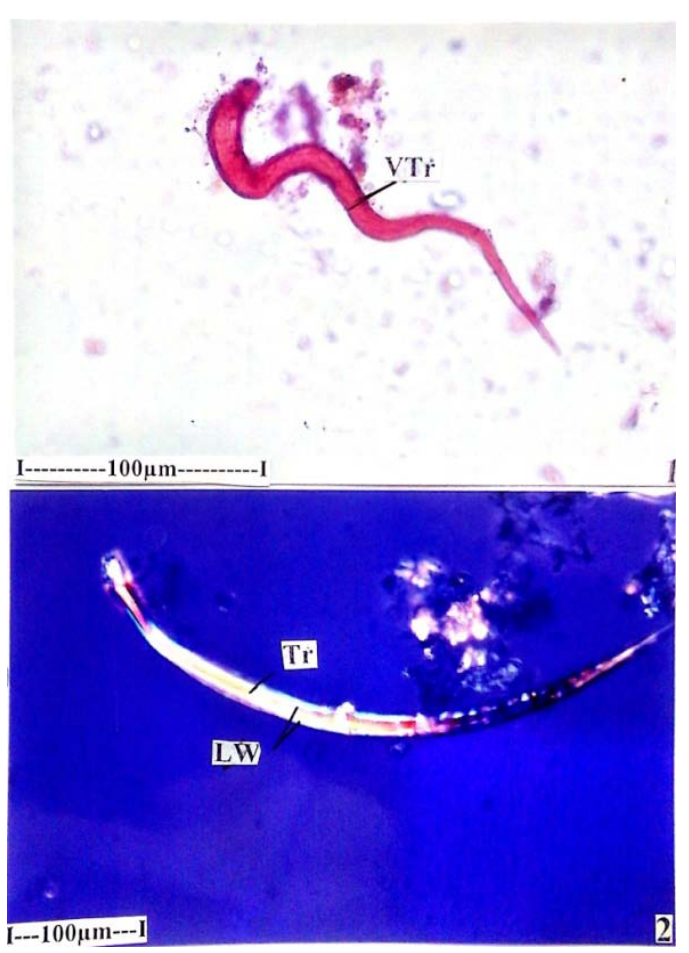

Fig. 4.1, 2

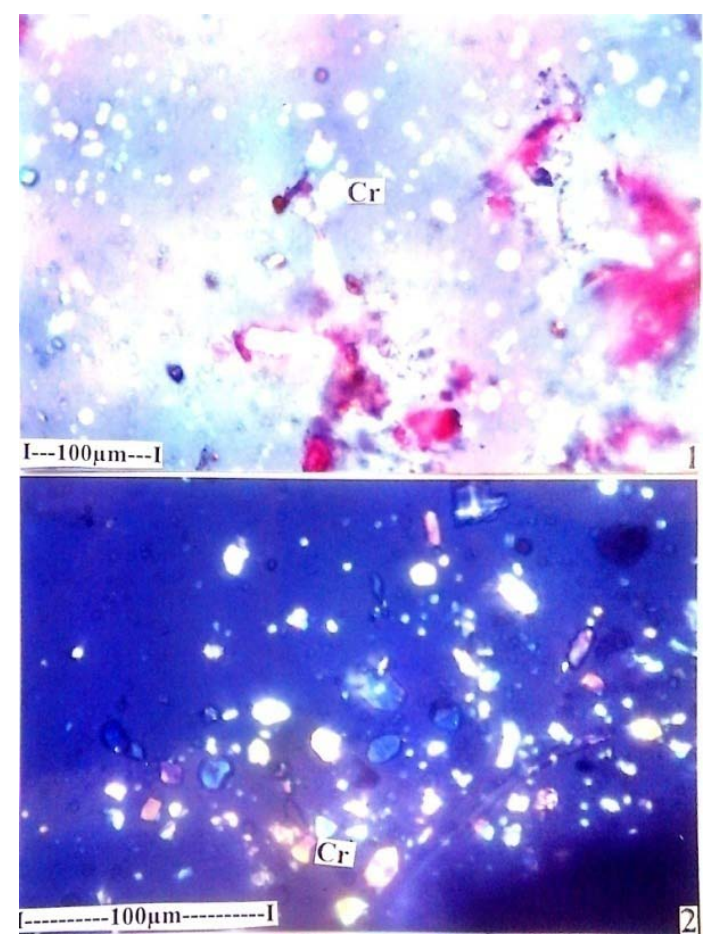

Fig. 5.1, 2

\section{Legend for fruit sample 1 micrographs:}

Fig. 1.1 A fruit with five cocci bearing pairs of strong spines.
1.2 A single coccus with a pair of long spines and a pair of short spines. Coe-Coccus; La-Lamettate zones; L Sp-Long spine; S Sp-Short spine. 
Fig. 2.1 A brachy sclereid.

2.2 Fibre tracheids are forming a bundle.

2.3 Brachy sclereid bundle, the sclereids being irregular in shape. CL-Cell lumen; Scl-Sclereids.

Fig. 3.1 A mass of parenchyma cells.

3.2 Long and short epidermal trichomes.

Pa-Parenchyma cells; Tr-Trichomes.

Fig. 4.1 Vermiform trichomes.

4.2 Trichome, seen under polarised light showing the lignifications of the cell walls.

LW-Lateral walls; Tr-Trichomes; V Tr-Vermiform trichomes.

Fig. 5.1 and 2: Calcium oxalate prismatic crystals in the powder as seen under polarised light.

Cr-Crystals.

Sample 2: The fruit sample from Karnataka State consists of five triangular cocci. Which are attached to each other along the central axis. The fruit is more densely woolly; even the spines have dense trichomes (fig. 2.1, 2).

Diameter of the fruit $10 \mu \mathrm{m}$

Radial length of coccus $6 \mu \mathrm{m}$

Thickness along tangential part $3 \mu \mathrm{m}$

Length of the long spine $4 \mu \mathrm{m}$

\section{Powder microscopic observations}

Fibre tracheids: The powder encloses only occasionally fibre tracheids, which are long, narrow and resemble the fibres in general appears. But sclereids have the wide lumen and many circular, simple pits. The Fibre tracheids are straight, or they may be somewhat undulate (fig. 2.1).

Brachy sclereids (fig. 2.2, 3): Sclereids which are shorter, wide and mostly irregularly lobed are abundant in the powder. Some of them are long and narrow with tapering ends (fig. 2.2). Others are wide short and much lobed (fig. 2.3). The sclereids have thick lignified walls and wide lumen. The sclereids are $15 \mu \mathrm{m}$ thick and $70 \mu \mathrm{m}$ long.

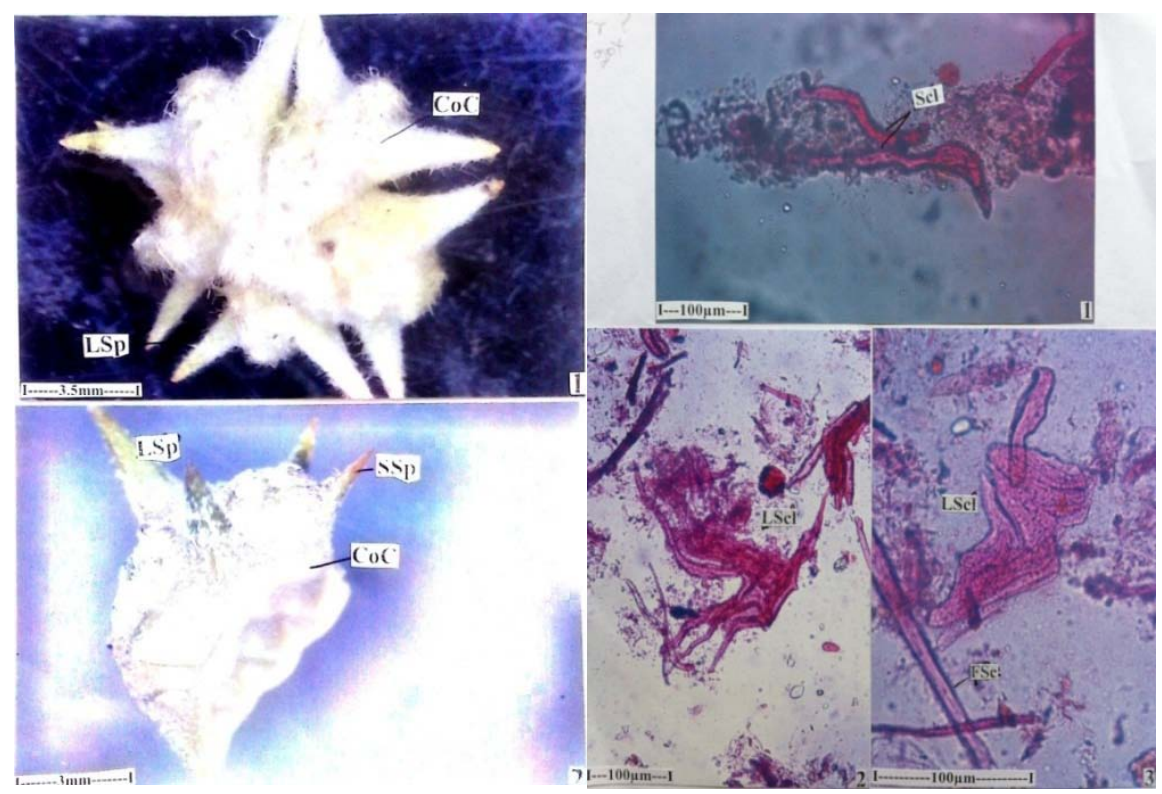

Fig. 1.1, 2

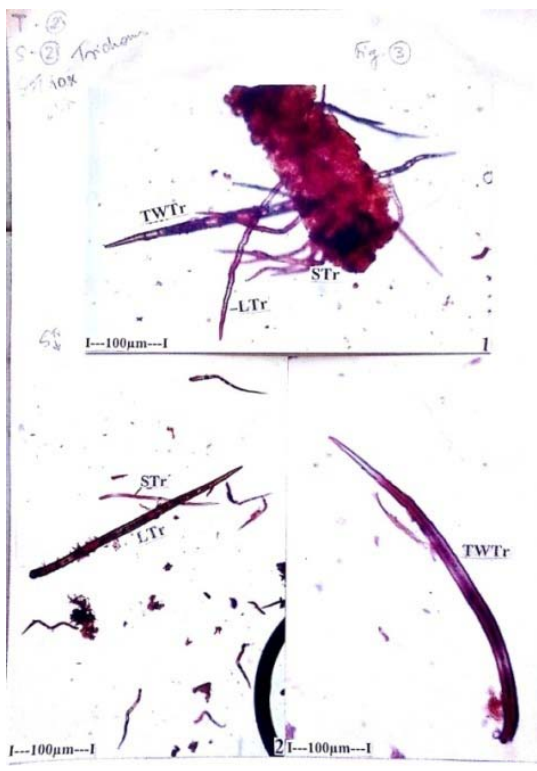

Fig. 3.1, 2, 3
Fig. 2.1, 2, 3

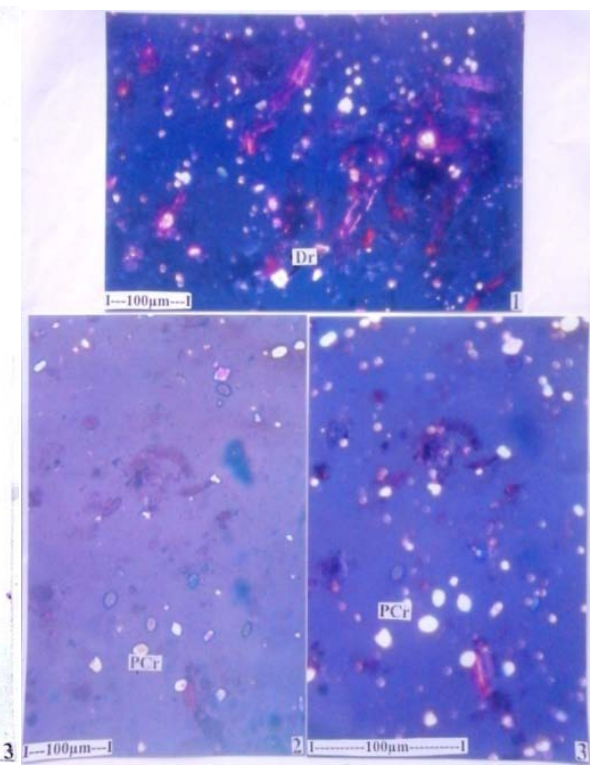

Fig. 4.1, 2, 3 


\section{Trichomes (fig. 3.1, 2, 3):}

Epidermal trichomes are abundant in the powder. The trichomes are of three types.

Short trichomes: Short trichomes are seen attached densely on the seed coat. They are thin-walled and flexuous, being undulate (fig. 3.1). The short trichomes are $80-160 \mu \mathrm{m}$ in length.

Long trichomes (fig. 3.1, 2): The long trichomes are straight and become pointed at the tip. These are minute echinate outgrowths on the outer surface of the long trichomes. The walls are thin, and the cell lumen is wide.

Thick walled trichomes (fig. 3.1, 3): Apart from short and long thin-walled trichomes, these are thick-walled trichomes in the powder. These trichomes have thick lignified walls and narrow lumen. The tip is pointed. The trichome is nearly $500 \mu \mathrm{m}$ long and 20 $\mu \mathrm{m}$ thick.

Calcium oxalate crystals (fig. 4.1, 2, 3): Calcium oxalate crystals of prismatic type and druses are plenty in the powder. The prismatic crystals are cuboidal, pyramidal and double pyramidal types. The druses are spherical bodies comprising minute spiny particles tightly packed into a spiny ball (fig. 4.1).

\section{Legend for sample 2 figures}

Fig. 1.1 A fruit showing five divergent cocci with long spines.

1.2 A single coccus with long thick spine and a pair of short spines.

Coe-Coccus; L Sp-Long spine; S Sp-Short spine.

Fig. 2.1 Fibre sclereids in the powder.

2.2 Lobed sclereids are forming a clump.

2.3 fibre sclereid and a bundle of lobed sclereids.

F Sc-Fibre sclereid; L Sc-Lobed sclereid; Scl-Sclereids.

Fig. 3.1 A thick piece of the pericarp of the fruit bearing short, long and thick-walled trichomes.

3.2 Long and short trichomes.

3.3 Thick-walled trichome.

L Tr-Long trichome; S Tr-Short trichome; T W Tr-Thick walled trichome.

Fig. 4.1 Calcium oxalate crystals in the powder-Druses.

4.2, 3 Calcium oxalate prismatic type of crystals.

Dr-Druses; P Cr-Prismatic crystals.
Sample 3: Sample 3 collected from Katumnorkoil, Tamilnadu State. The fruit is flat and circular formed by five cocci, which are laterally fused. Each coccus is triangular with the wide end being centrifugal in position. The coccus has two long, thick, sharp spines and two short spines. The fruit is tomentose; the tomentum is less when compared with samples 2 and 1.

Diameter of the fruit $7 \mathrm{~mm}$

Radial length of the coccus $2 \mathrm{~mm}$

Length of the long spine $3 \mathrm{~mm}$

Thickness of the coccus $550 \mu \mathrm{m}$

Powder Microscopic observations: The powder includes the following inclusions:

Parenchyma cells: Wide elliptical thick-walled parenchyma cells are common in the powder. These cells are seen in small clusters. These cells are $60 \times 110 \mu \mathrm{m}$ in size (fig. 2.1).

Polygonal, thick-walled cells are also seen in the powder (fig. 2.2). These cells have wide, empty lumen. The cells are $40 \mu \mathrm{m}$ in diameter.

Epidermal cells of the seed coat are seen in the form of a thin plate (fig. 3.1). The epidermal cells are polyhedral, thin walled and compact.

Sclerenchymatous cells: Sclerenchymatous inner seed coat cells are in small clusters. They are hexagonal to pentagonal in outline. The cell walls are thick and lignified. The cells are $30 \mu \mathrm{m}$ wide.

Fibre sclereids (fig. 4.1, 2): Fibre sclereids are long, narrow, thickwalled cells with pointed ends are seen either as individual cells or as small bundles. Since these cells resemble fibres in shape and size but possess wide lumen with simple pits, they are called fibre sclereids. The cells are $400 \mu \mathrm{m}$ long and $12 \mu \mathrm{m}$ thick. The sclereids that form the thick and strong spines are also seen in the thick loose bundle (fig. 5.1).

Epidermal trichomes: Epidermal trichomes are seen either in attached to the fruit (fig. 5.2) or free from the fruit (fig. 6.2). The trichomes are short or long, but thin walled. These are also long highly thick-walled. The walls of all types of trichomes are lignified (fig. 5.2). Short trichomes are $80 \mu \mathrm{m}$; long trichomes are $160 \mu \mathrm{m}$. Thick-walled trichomes are $420 \mu \mathrm{m}$.

Crystals (fig. 7.1, 2): Calcium oxalate crystals are widespread in the powder. They are mostly prismatic types. They range from cubical, ellipsoidal and spherical. The elongated crystals are $10 \times 30 \mu \mathrm{m}$ in size; the spherical crystals are $25 \mu \mathrm{m}$ in diameter.

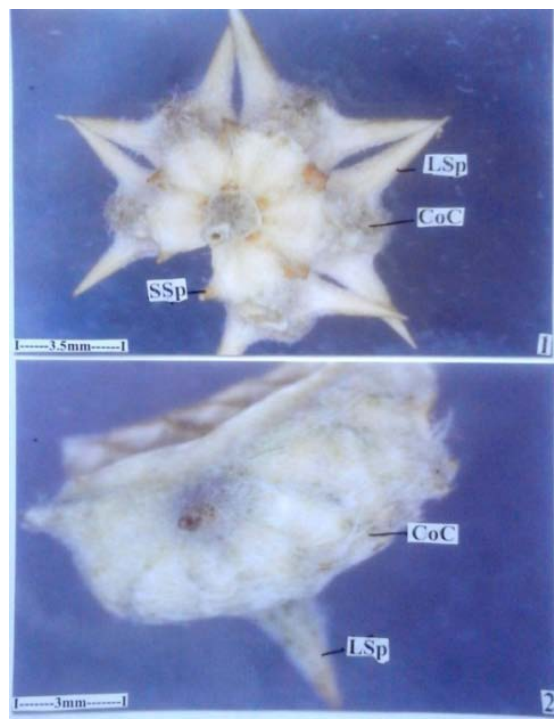

Fig. 1.1, 2

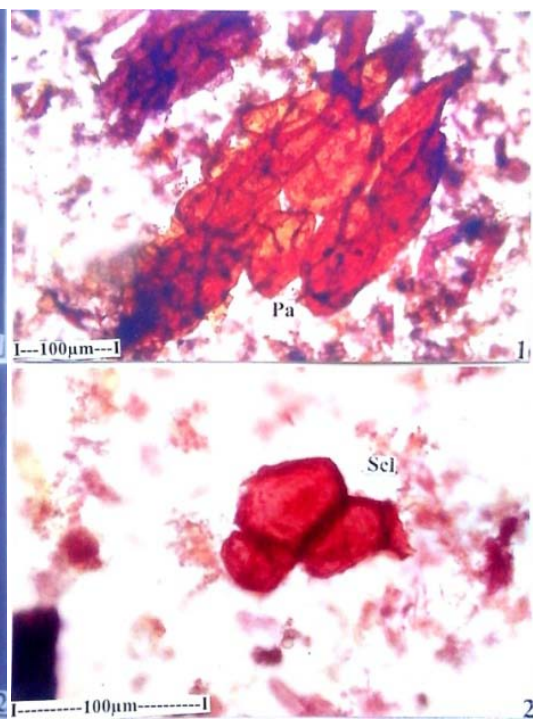

Fig. 2.1, 2 


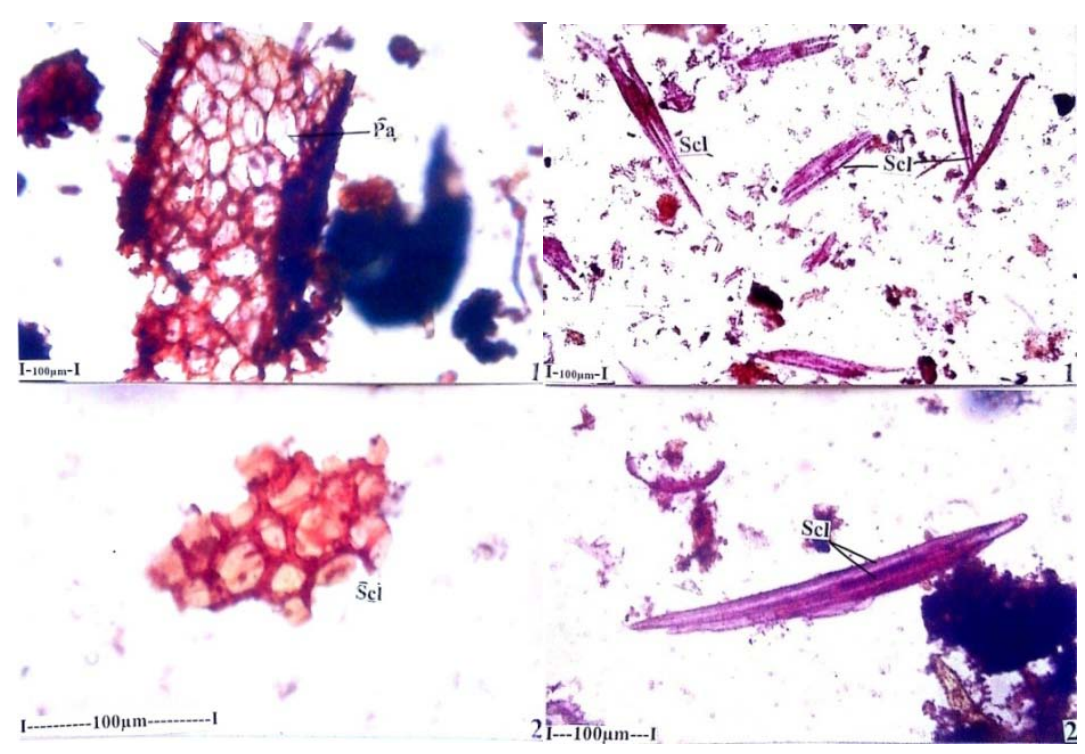

Fig. 3.1, 2

Fig. 4.1, 2

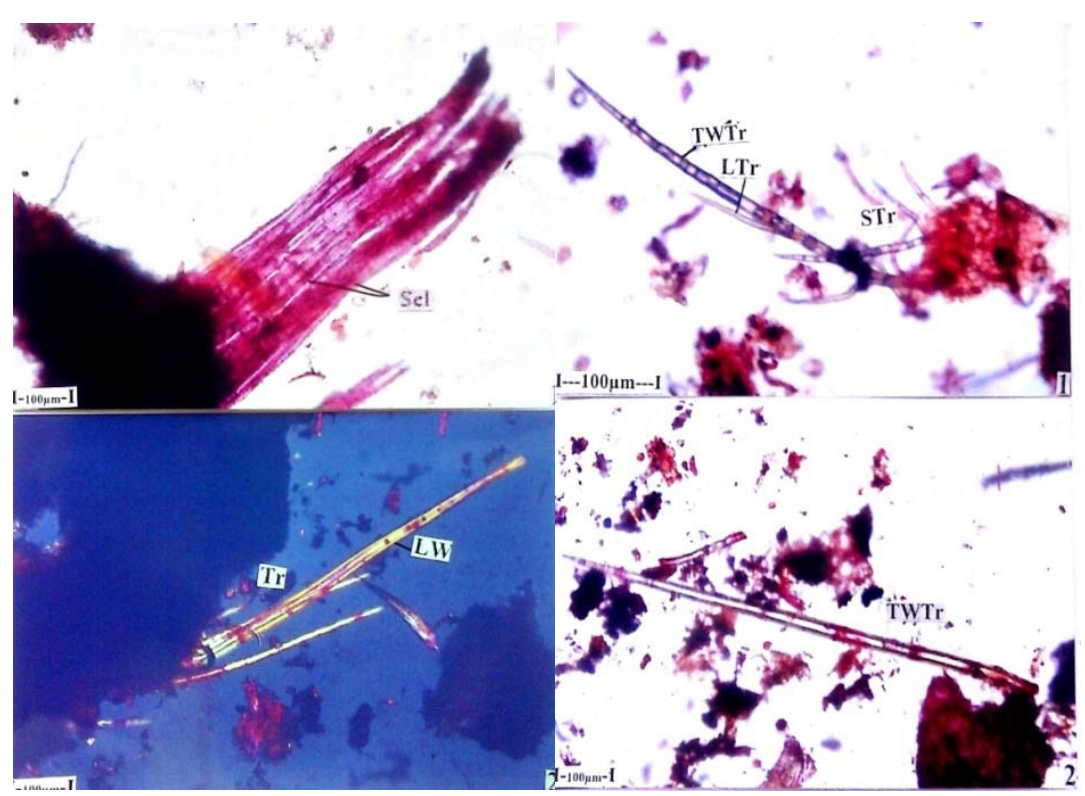

Fig. 5.1, 2

Fig. 6.1, 2

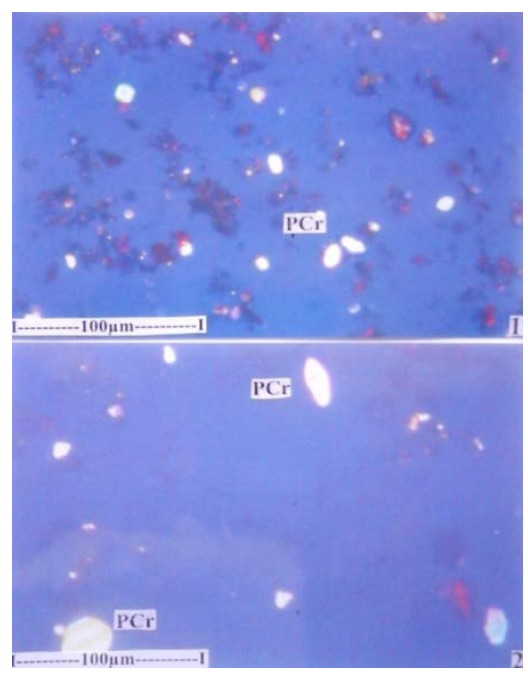

Fig. 7.1, 2 


\section{Legend for the figures: Sample 3}

Fig. 1.1 An entire view with five cocci and their spines.

1.2 A single coccus enlarged showing long spine.

Coe-Coccus; L Sp-Long spine; S Sp-Short spine.

Fig. 2.1 Parenchyma cells.

2.2 Sclerenchyma cells.

Pa-Parenchyma; Scl-Sclerenchyma.

Fig. 3.1 Epidermal cells of the outer seed coat in surface view.

3.2 Sclerotic inner seed coat in surface view.

Pa-Parenchyma; Scl-Sclerenchyma.

Fig. 4.1 Fibre sclereids-isolated cells.

4.2 Fibre sclereids in the bundle.

F Sc-Fibre sclereids.

Fig. 5.1 Fibre sclereids of the spine.

5.2 Epidermal trichomes as seen under polarised light to show the lignified walls.

LW-Lignified walls; Scl-Sclereids; Tr-Trichomes.

Fig. 6.1 A cluster of long, short and long thick-walled trichomes attached on the fruit.

6.2 A single long thick-walled trichome.

L Tr-Long trichome; S Tr-Short trichome; T W Tr-Thick walled long trichome.

Fig. 7.1, 2 Calcium oxalate prismatic crystals are seen in the powder.

P cr-Prismatic crystals.

\section{DISCUSSION}

The main differences were observed in all 3 fruit samples in terms of quantity and size of all cell inclusions. The length of fibre sclereids in sample 3 was high when compared to sample 1 and 2. Brachy sclereids in sample 3 are less in number with compared to sample 1 and 2. Thick wall masses of parenchyma cells are more common in sample 3 when to compare to sample 1 . Trichomes are abundant in all three samples with different sizes. Prismatic calcium oxalate crystals are seen in all 3 samples. Sample 1 shows rhomboidal and cuboidal types of crystals. In sample 2 calcium oxalate crystals are ranges from cuboidal, pyramidal and double pyramidal types. Cuboidal, ellipsoidal and spherical crystals are more common in sample 3. Fibre sclereids in sample 1 show long narrow thick-walled with wide cell lumen containing tapering ends, wide lumen with simple pits are seen in sample 2 and thick-walled cells with pointed ends are observed in sample 3 . The size of the fruit collected from the Chennai region was smaller than fruits collected from Karnataka and Telangana states, which were clearly identified in micromorphological features. Chandima Wijayasiriwardena et. al studied the detailed comparative powder microscopy of rhizomes of Alpinia species to highlight important anatomical characters.

\section{CONCLUSION}

From the present study, it is revealed that the geographical variation of Tribulus terrestris fruit samples from three regions of South India shows similar powder microscopic characters. The geographical variation is associated with morphological features of the plant. However, the distribution of sclereids, trichomes, prismatic calcium oxalate crystals are varying from sample to sample. Hence the calcium oxalate crystals, trichomes, sclereids are useful in confirming identity and purity. Based on the powdered microscopic comparison, the data evolved from the current investigation may be utilised for the standardisation of the Tribulus terrestris fruit samples in the powdered form in order to ensure the quality of the powdered crude drug during formulation and also laying down pharmacopoeial standards for the fruits of Tribulus terrestris $\mathrm{L}$.

\section{ACKNOWLEDGMENT}

We are deeply thankful to the department of pharmacy, Annamalai University for providing facilities to an outcome this work.

\section{CONFLICT OF INTERESTS}

No conflict of interest

\section{REFERENCES}

1. JK Gupta, PK Sharma, SH Ansari. Standardisation of the fruit of Triblus terrestris Linn. Asian J Chem 2005;17:975-9.

2. Jayanthy A, Deepak M. Pharmacognostic characterization and comparison of fruits of Tribulus terrestris L. and Pedalium murex L. Int J Tradit Herb Med 2013;1:29-34.

3. Amit Joshi, AK Pathak, Mukul Tailang. Comparative pharmacognostic characterization of selected species of Ocimun. J Drug Delivery Ther 2014;4:72-80.

4. Jayanthy, Prakash Kumar U, AB Remashree. Seasonal and geographical variations in cellular characters and chemical contents in desmodium gangeticum (L.) DC.-an ayurvedic medicinal plant. Int J Tradit Herb Med 2013;2:34-7.

5. Kripa KG, Sangeetha R, Chamundeeswari D. Pharmacognostical and phytochemical evaluation of the plant Leucas aspera. Asian J Pharm Clin Res 2016;9:263-8.

6. Jignesh Kevalia, Bhupesh Patel. Identification of fruits of Tribulus terrestris Linn. and pedalium murex Linn: a pharmacognostic approach. Ayu 2011;32:550-3.

7. Azhagu Raman Chidambaram, Ajithadas Aruna. Pharmacognostic study and development of quality parameters of whole plants of Trichodesma indicum (linn.) R. br. Asian J Pharm Clin Res 2013;6:167-9.

8. Mandal Bitasta, Madan Swati. Comparative standardisation and physicochemical evaluation of the leaves of Stevia rebaudiana Bertoni from different geographical sources. Pharmacogn J 2011;3:21-6.

9. Chandra Kala, Syed Salman Ali, Sudhir Chaudhary. Comparative pharmacognostic evaluation of Costus speciosus (Wild Ginger) and Zingiber officinale (Ginger) Rhizome. Int J Curr Pharm Res 2016;8:19-23.

10. Chandima Wijayasiriwardena, Sirimal Premakumara. Comparative powder microscopy of Alpinia calcarata Roscoe and Alpinia galanga (Linn.) Willd Ayu 2012;33:441-3.

11. TPO Brien, N Feder, ME McCully. Polychromatic staining of plant cell walls by toluidine blue O. Protoplasma 1964; 59:367-73.

12. Metcalfe CR, Chalk L. Anatomy of the dicotyledons. Vol. I. Oxford; Clarendon Press; 1979.

13. Sass JE. Elements of botanical microtechnique. 2nd edn. New York: McGraw-Hill Book Co; 1940.

14. Easu K. Anatomy of seed Plants. New York: John Wiley and sons; 1979.

\section{How to cite this article}

- $\quad$ Suresh Reddy Yanala, D Sathyanarayana. Powder microscopic studies of the fruits of tribulus terrestris linn collected from different geographical locations of South India-a comparative stdy. Int J Pharm Pharm Sci 2017;9(1):158-164. 